\title{
Principles of Melting in Hybrid Organic-Inorganic Perovskite and Polymorphic ABX3 Structures
}

Received 00th January 20xx, Accepted 00th January 20xx
Bikash Kumar Shaw, ${ }^{a}$ Celia Castillo-Blas, ${ }^{a, b}$ Michael F. Thorne, ${ }^{a}$ María Laura Ríos Gómez, ${ }^{a}$ Tom Forrest, ${ }^{\mathrm{c}}$ Maria Diaz Lopez, ${ }^{\mathrm{c}}$ Philip A. Chater, ${ }^{\mathrm{c}}$ Lauren N. McHugh, ${ }^{\mathrm{a}}$ David A. Keen, ${ }^{\mathrm{d}}$ and Thomas D. Bennett*a

Four novel dicyanamide-containing hybrid organic-inorganic ABX3 structures are reported, and the thermal behaviour of a series of nine perovskite and non-perovskite $A B X 3$ structures in total are analysed. Structure-property relationships are investigated by varying both A-site organic and B-site transition metal cations. The introduction of larger tetraalkylammonium cations into the A-site reduces the melting temperature, and raises the Tolerance Factor. Total scattering methods are used to provide a greater understanding of the melting mechanism.

\section{Introduction}

Hybrid organic-inorganic perovskites (HOIPs) are a huge class of crystalline materials with general formula $A B X_{3}$, where $A, B$ and $X$ are an organic cation, metal cation and multidentate inorganic or organic anion, respectively. HOIPs have recently emerged as efficient optoelectronic materials thanks to their valuable utility in to ionic transport, $^{1,2}$ multiferroic $^{3}$ and photovoltaic applications. ${ }^{4-7}$ They possess a high chemical and structural variability through the replacement of the $X$ species with other multidentate bridging ligands such as cyanide [ $\left.\mathrm{CN}^{-}\right]$, thiocyanate $\left[\mathrm{SCN}^{-}\right]$, formate $\left[\mathrm{HCOO}^{-}\right]$, hypophosphite $\left[\mathrm{H}_{2} \mathrm{POO}^{-}\right]$or dicyanamide [dca, $\left.\mathrm{N}(\mathrm{CN})_{2}^{-}\right]$, among others. $^{8-11}$ Careful selection, or modification of the linker and/or metal cation allows property modulation and enhancement. ${ }^{12}$

The extended hybrid connectivity of HOIPs mean that they share many similarities with metal-organic frameworks (MOFs). ${ }^{13-15}$ However, HOIPs are considerably more dense than MOFs given the presence of the A-site cation, which means they are typically unable to selectively adsorb guest species. ${ }^{16}$ Accordingly, interest in their behaviour does not revolve around porosity, but instead concentrates on ionic conductivity, ${ }^{1}$ ferroelectric ${ }^{17}$ and barocaloric ${ }^{18}$ properties.

Phase transitions between crystalline HOIP polymorphs upon application of external stimuli such as temperature or pressure are relatively common. Such transitions are commonly associated with, amongst other factors, displacement of the organic A site cation, and a large anisotropic thermal expansion. ${ }^{18}$ For example, [TPrA] $\left[\mathrm{Mn}(\mathrm{dca})_{3}\right]\left(\operatorname{TPrA}=\right.$ tetrapropylammonium, $\left.\left[\left(\mathrm{CH}_{3} \mathrm{CH}_{2} \mathrm{CH}_{2}\right)_{4} \mathrm{~N}\right]^{+}\right)$, displays a first-order structural phase transition at $57^{\circ} \mathrm{C}$ from a non-

\footnotetext{
a. Department of Materials Science and Metallurgy, University of Cambridge, CB3 OFS, UK.

b. Departamento de Química Inorgánica, Universidad Autónoma de Madrid, 28049 Madrid, Spain.

c. Diamond Light Source Ltd, Diamond House, Harwell Campus, Didcot, Oxfordshire, OX11 ODE, UK.

d. ISIS Facility, Rutherford Appleton Laboratory, Harwell Campus, Didcot, Oxfordshire, OX11 OQX, UK.
}

centrosymmetric structure (space group $P 42_{1} c$ ), to a high temperature polymorph with the centrosymmetric space group $14 / \mathrm{mcm}^{19}$

Despite the dominance of the solid crystalline state in the family, several HOIPs have recently been demonstrated the ability to melt into liquid phases. ${ }^{21,22}$ This is unusual given the thermal decomposition observed prior to melting in most organic-inorganic networks. ${ }^{23,24}$ Dicyanamide-based hybrid organic-inorganic $\mathrm{ABX}_{3}$ structures containing both tributylmethylammonium and tetrapropylammonium as the 'A-site' cation have however been shown to undergo melting upon heating. ${ }^{21,22}$ The $[\operatorname{TPrA}]\left[\mathrm{M}(\mathrm{dca})_{3}\right]$ ( $\mathrm{M}$ $=\mathrm{Mn}, \mathrm{Fe}, \mathrm{Co}$ ) series melt at temperatures $\sim 250{ }^{\circ} \mathrm{C}$, via $\mathrm{M}-\mathrm{N}$ coordination bond breaking and the formation of under-coordinated $M$ centres. Interestingly, cooling of these high temperature liquids back to room temperature results in glass formation. Importantly, and differentiating them from glasses formed by melt-quenching MOFs, ${ }^{25-28}$ they exhibit interesting electronic/phononic properties with potential applications in e.g. thermoelectrics. ${ }^{22}$

In this work, we look to lower melting temperatures through careful modification of A-site and B-site species. Specifically, we investigate the structure-property correlation between hybrid organic-inorganic $\mathrm{ABX}_{3}$ structures with different chemical compositions and their melting and glass transition temperatures $\left(T_{\mathrm{m}}\right.$ and $T_{\mathrm{g}}$ ). We modify the size of the organic A cation in [TAIA] [M(dca $)_{3}$ ] (TAIA = tetralkylammonium linker, $M=M n, F e, C o$ ) structures through the introduction of successively larger tetrabutylammonium (TBuA = tetrabutylammonium, $\left.\left(\mathrm{CH}_{3} \mathrm{CH}_{2} \mathrm{CH}_{2} \mathrm{CH}_{2}\right)_{4} \mathrm{~N}^{+}\right)$and tetrapentylammonium (TPnA $=$ tetrapentylammonium, $\left.\left(\mathrm{CH}_{3} \mathrm{CH}_{2} \mathrm{CH}_{2} \mathrm{CH}_{2} \mathrm{CH}_{2}\right)_{4} \mathrm{~N}^{+}\right)$species (Fig. 1). This results in a series of nine $\mathrm{ABX}_{3}$ structures, of which four are previously unreported. Structural characterisation techniques allow Tolerance Factors to be calculated for each, which are then linked to thermal analysis in order to rationalize the reduction in $T_{\mathrm{m}}$ upon increasing A cation size. ${ }^{29}$ 

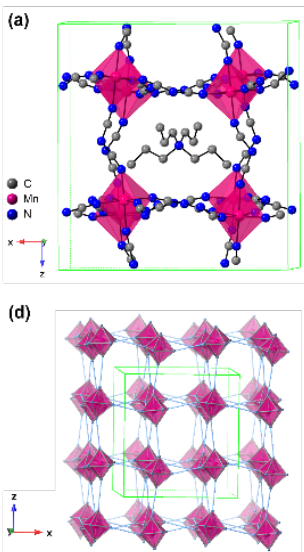

[TPrA][Mn(dca) $]$ 6 corner-linked
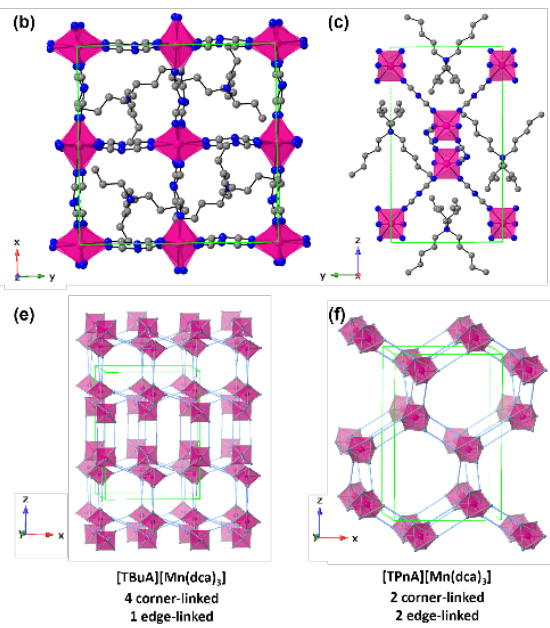

Figure. 1 Simplified structure of (a) $[\operatorname{TPrA}]\left[\mathrm{Mn}(\mathrm{dca})_{3}\right]$, (b) [TBuA][Mn(dca) $\left.)_{3}\right]$ and (c) $[\mathrm{TPnA}]\left[\mathrm{Mn}(\mathrm{dca})_{3}\right]$ at $298 \mathrm{~K}$ respectively. ${ }^{29}$ All $\mathrm{H}$ atoms have been omitted for clarity. Only one orientation of the tetraalkylammonium and dca ions within the average crystal structure are shown for each $\mathrm{ABX}_{3}$ structure even though the average structures may have multiple orientations. Unit cells are indicated by green lines. (d) - (f) Indicate the polyhedral connectivity of each structure.

\section{Results and Discussion}

\section{Synthesis and Crystallography}

The synthesis of all [TAIA][M(dca $\left.)_{3}\right]$ materials was performed by solvent layering, and through equimolar replacement of precursor quantities in each case. ${ }^{30}$ Typically, $10 \mathrm{~mL}$ of an aqueous solution $(2$ $\mathrm{mmol}$ ) of the metal salt was placed at the bottom of a thin crystallization tube, and layered with a mixture of a sodium dicyanamide solution in $10 \mathrm{~mL}$ of water $(6 \mathrm{mmol})$ and the tetraalkylammonium bromide in $10 \mathrm{mmol}$ of ethanol $(2 \mathrm{mmol})$. Block-shaped single crystals were isolated from the mother liquor after one week of slow evaporation in an open atmosphere at $298 \mathrm{~K}$. $[\operatorname{TPR} A]\left[\mathrm{Mn}(\mathrm{dca})_{3}\right]$, crystallizes in the previously reported tetragonal structure in the $P 42_{1} C$ space group at room temperature (Fig. 1a; $a=$ 16.29 $\AA, c=17.43 \AA$; Table 1). ${ }^{22}$ Here the dca ligand bridges metal centres through nitrogen atoms in a $\mu 1,5$ end-to-end fashion. This means that neighboring metal-centered octahedra are cornersharing, and create a pseudo-cubooctahedral cavity in which the tetraalkylammonium cation (TAIA) is located (Fig. 1d-f).

Table 1. Chemical and physical properties for the nine $[\mathrm{TAIA}]\left[\mathrm{M}(\mathrm{dca})_{3}\right]$ compounds in this study.

\begin{tabular}{|c|c|c|c|c|c|c|c|c|}
\hline A & B & Space Group & Structure Type & $\begin{array}{l}T_{\mathrm{d}} \\
\left({ }^{\circ} \mathrm{C}\right)\end{array}$ & $\begin{array}{l}T_{\mathrm{m}} \\
\left({ }^{\circ} \mathrm{C}\right)\end{array}$ & $\begin{array}{l}\Delta H_{\mathrm{f}} \\
\left(\mathrm{kJ} \mathrm{mol}^{-1}\right)\end{array}$ & $\begin{array}{l}\Delta S_{\mathrm{f}} \\
\left(\mathrm{J} \mathrm{mol}^{-1} \mathrm{~K}^{-1}\right)\end{array}$ & Ref \\
\hline TPrA & $\mathrm{Mn}$ & $P 42_{1} C$ & Perovskite & $281^{a}$ & $262^{a}$ & $47^{a}$ & $88^{a}$ & 19,30 \\
\hline TPrA & $\mathrm{Fe}$ & Pnna & Perovskite & $271^{a}$ & $252^{a}$ & $50^{a}$ & $95^{a}$ & 17 \\
\hline TPrA & Co & Pnna & Perovskite & $267^{a}$ & $212^{a}$ & $65^{a}$ & $134^{\mathrm{a}}$ & 17 \\
\hline TBuA & $\mathrm{Mn}$ & $P 2{ }_{1} 2_{1} 2$ & Triple Rutile & 282 & 185 & 59 & 128 & 30 \\
\hline TBuA & $\mathrm{Fe}$ & $P 2{ }_{1} 2{ }_{1} 2$ & Triple Rutile & 271 & 175 & 60 & 134 & This work \\
\hline TBuA & Co & $P 2{ }_{1}{ }_{12}$ & Triple Rutile & 271 & 143 & 63 & 152 & This work \\
\hline TPnA & $\mathrm{Mn}$ & Pnna & $\mathrm{LiSbO}_{3}$ & 283 & 149 & 56 & 132 & 30 \\
\hline TPnA & $\mathrm{Fe}$ & Pnna & $\mathrm{LiSbO}_{3}$ & 273 & 137 & 61 & 149 & This work \\
\hline TPnA & Co & Pnna & $\mathrm{LiSbO}_{3}$ & 272 & 106 & 59 & 155 & This work \\
\hline
\end{tabular}

${ }^{a}$ The values were taken from our previous report. ${ }^{22}$
On the other hand, [TBuA] $\left[\mathrm{Mn}(\mathrm{dca})_{3}\right]$ crystallizes in the orthorhombic space group $P 2{ }_{1} 2{ }_{1} 2, a=16.01 \AA, b=16.01 \AA, c=21.55$ $\AA$ (Fig. 1b). This is not a perovskite structure, but instead adopts a distorted triple rutile topology. The $\mathrm{Mn}$ coordination sphere contains three crystallographically independent $\mu 1,5 \mathrm{dca}$ anions. Each is joined to five $\mathrm{Mn}$ atoms. One is through a doubly bridged dca ligand, which creates an edge sharing $\mathrm{MnN}_{6}$ dimer unit. The further connection of each $\mathrm{Mn}$ centre to four additional atoms through single $\mu 1,5$ dca ligands then creates a 3D anionic framework. Hexagonal channels contain the TBuA cation.

[TPnA] $\left[\mathrm{Mn}(\mathrm{dca})_{3}\right]$ crystallizes in the Pnna space group, $a=13.22$ $\AA, b=11.63 \AA, c=20.31 \AA$ (Fig. 1c), and adopt a $\mathrm{LiSbO}_{3}$ structure. Here, each octahedral $\mathrm{Mn}$ coordination environment contains three crystallographically independent nitrile groups. These octahedra share edges with two neighbouring $\mathrm{Mn}$ coordination spheres through double $\mu 1,5$ dca ligands, which creates a zigzag chain motif. They also share edges with two additional $\mathrm{Mn}$ octahedra through single $\mu 1,5$ dca ligands, which link these chains together.

Fe and $\mathrm{Co}$ analogues of [TPrA] $\left[\mathrm{Mn}(\mathrm{dca})_{3}\right]$, possess the Pnna space group, with cell parameters: $a=11.52 \AA, b=11.54 \AA, c=17.44 \AA$ and $a=17.22 \AA, b=23.13 \AA, c=22.85 \AA$ for [TPrA] $\left[\mathrm{Fe}(\mathrm{dca})_{3}\right]$ and $[\operatorname{TPr} A]\left[\mathrm{Co}(\mathrm{dca})_{3}\right]$, respectively, according to previous reported structures. ${ }^{17}$ On the other hand, $\mathrm{Fe}$ and Co analogues of [TBuA] $\left[\mathrm{Mn}(\mathrm{dca})_{3}\right]$ and $[\mathrm{TPnA}]\left[\mathrm{Mn}(\mathrm{dca})_{3}\right]$ materials have not been previously reported.

In this work, single crystal X-ray diffraction studies (Fig. S1 - S6 and Tables S1 - S4) confirmed the successful synthesis of these four structures ([TBuA][Fe(dca) $\left.)_{3}\right],[\mathrm{TBuA}]\left[\mathrm{Co}(\mathrm{dca})_{3}\right],[\mathrm{TPnA}]\left[\mathrm{Fe}(\mathrm{dca})_{3}\right]$ and $\left.[\mathrm{TPnA}]\left[\mathrm{Co}(\mathrm{dca})_{3}\right]\right)$. We confirmed that, similar to [TBuA][Mn(dca $\left.)_{3}\right]$, both [TBuA][Fe(dca) $\left.)_{3}\right], a=15.7971(7) \AA, b=15.8093(9) \AA, c=$ $21.4138(11) \AA$ and [TBuA] [Co(dca) $\left.)_{3}\right], a=15.7659(6) \AA, \quad b=15.7712(5)$ $\AA, c=21.2815(7) \AA$ crystallise in the $P 2{ }_{1} 2_{1} 2$ space group.

Likewise, as [TPnA][Mn(dca) $\left.)_{3}\right],[\mathrm{TPnA}]\left[\mathrm{Fe}(\mathrm{dca})_{3}\right](a=13.1007(6)$ $\AA$, $b=11.6128(5) \AA, c=20.0929(8) \AA)$ and [TPnA] [Co(dca) 3 ] $(a=$ 13.066(2) $\AA, b=11.6026(19) \AA, c=19.926(4) \AA$ ) crystallises in the Pnna space group. In all cases, alkyl chains contain structural disorder, which is accentuated in the case of longer chains.

The cell parameters obtained were then used in a Pawley refinement of powder X-ray diffraction data collected on bulk samples (Fig. S7 and S8), to confirm phase purity of in each case. Altogether, these compounds, in addition with the previously reported [TPrA] $\left[\mathrm{M}(\mathrm{dca})_{3}\right]$ series (Table 1) provide an opportunity to relate chemical composition to changes in physical properties.

Thermogravimetric analysis (TGA) and differential scanning calorimetry (DSC) experiments were carried out on the 

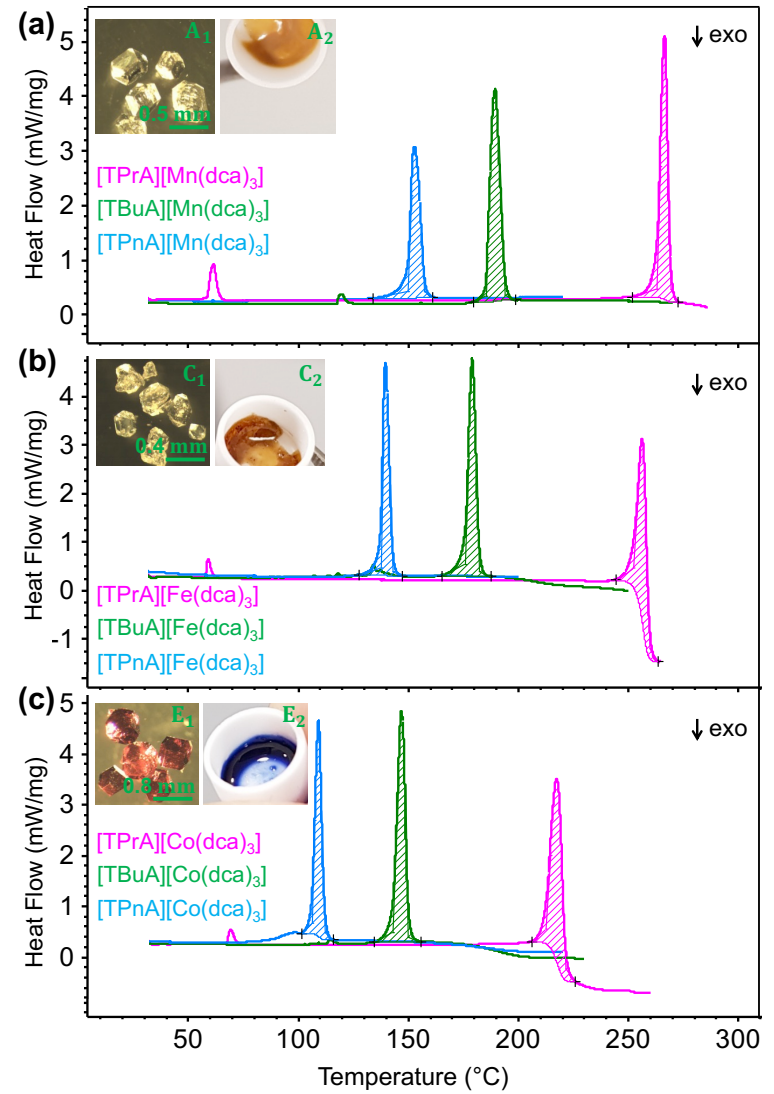

Figure. 2 (a) - (c) The change in heat flow as a function of temperature for the [TBuA][M(dca $\left.)_{3}\right]$ and $[\operatorname{TPnA}]\left[\mathrm{M}(\mathrm{dca})_{3}\right]_{3}$ samples synthesized in this study, alongside previously reported data for $[\operatorname{TPr} A]\left[\mathrm{M}(\mathrm{dca})_{3}\right] .^{22}$ Inset of (a), (b) and (c) shows the optical images of crystalline solid and molten liquid (taken instantly after opening the heating furnace at high-T near $T_{\mathrm{m}-\text { offset }}$ ) for [TBuA][ $\left.\mathrm{Mn}(\mathrm{dca})_{3}\right],[\mathrm{TBuA}]\left[\mathrm{Fe}(\mathrm{dca})_{3}\right]$ and [TBuA][Co(dca $\left.)_{3}\right]$ respectively. Optical images for all other materials $\left(B_{1}-F_{1}, B_{2}-F_{2}\right)$ are given in Fig. S10.

[TBuA][M(dca $\left.)_{3}\right]$ and $[\mathrm{TPnA}]\left[\mathrm{M}(\mathrm{dca})_{3}\right]$ samples. On subsequent data analysis, values for $T_{\mathrm{m}}$, the enthalpy of fusion $\left(\Delta H_{\mathrm{f}}\right)$, the entropy of fusion $\left(\Delta S_{f}\right)$ and the temperature of decomposition $\left(T_{d}\right)$, were identified (Fig. 2, Table 1). A decreasing trend in $T_{m}$ values with the increasing number of carbons in $A$ site chains is evident, i.e. $[\mathrm{TPnA}]\left[\mathrm{M}(\mathrm{dca})_{3}\right]<[\mathrm{TBuA}]\left[\mathrm{M}(\mathrm{dca})_{3}\right]<[\operatorname{TPrA}]\left[\mathrm{M}(\mathrm{dca})_{3}\right]$. Though linear trends across all nine compounds were not observed, the lowering of $T_{\mathrm{m}}$ is in general consistent with larger values of $\Delta \mathrm{S}_{\mathrm{f}}$, themselves ascribed to the progressively more restricted conformations of the larger organic cations in the solid state. This is consistent with the rational adopted by Mason et al in their network-forming bis(acetamides). ${ }^{31,32}$

Any trends in $\Delta H_{\mathrm{f}}$ and alkyl chain length are less clear, though are not perhaps expected given the proposal that melting does not directly involve bond breaking within the alkylammonium cation itself, but rather the $\mathrm{M}-\mathrm{N}$ coordination bonds in the surrounding framework (Fig. 3).

Trends upon changing the $B$ site transition metal ion are also present within each tetraalkylammonium set (TPrA, TBuA and TPnA). The trend in $T_{\mathrm{m}}$ is the same in each case, i.e. Co $<\mathrm{Fe}<\mathrm{Mn}$. These reductions were however, more subtle than the effect of changing the A site cation, resulting in for example a lowering in $T_{\mathrm{m}}$ from 150 ${ }^{\circ} \mathrm{C}$ for $[\mathrm{TPnA}]\left[\mathrm{Mn}(\mathrm{dca})_{3}\right]$, to $137^{\circ} \mathrm{C}$ for $[\mathrm{TPnA}]\left[\mathrm{Fe}(\mathrm{dca})_{3}\right]$ and then to $106{ }^{\circ} \mathrm{C}$ for $[\mathrm{TPnA}]\left[\mathrm{Co}(\mathrm{dca})_{3}\right]$ (Table 1). This follows the trend in ionic radius, which decreases in the order $\mathrm{Mn}>\mathrm{Fe}>\mathrm{Co}$ and consistent with hard-soft/acid-base theory as suggested previously. ${ }^{22}$

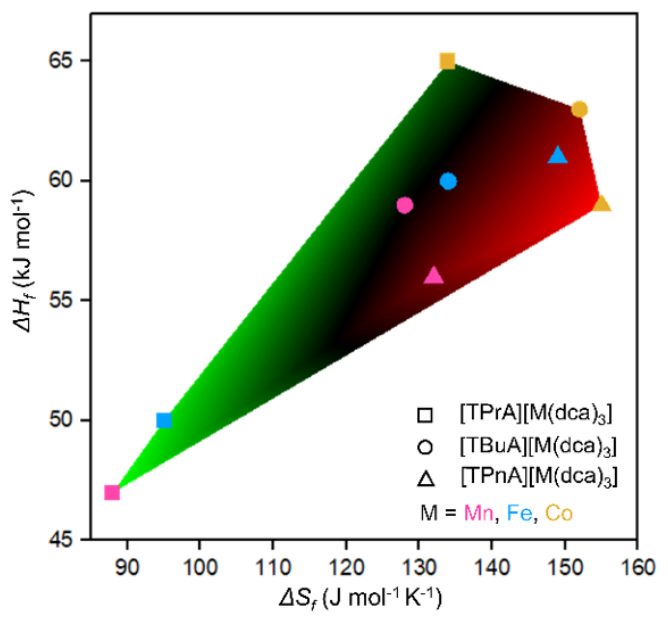

$T_{m}\left({ }^{\circ} \mathrm{C}\right)$

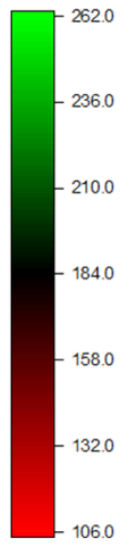

Figure. 3 Comparison of $\Delta H_{\mathrm{f}}, \Delta S_{\mathrm{f}}$, and $T_{\mathrm{m}}$ for the series [TAIA] [M(dca $\left.)_{3}\right]$. The symbol identifies the tetraalkylammonium cation and the symbol colour designates the metal.

\section{Structural Changes upon Melting}

To provide an atomic level insight into the changes in bonding upon heating into the liquid state $\mathrm{X}$-ray total scattering experiments were performed on the crystalline $A B X_{3}$ structures. Variable temperature total scattering measurements were carried out on [TBuA] $\left[\mathrm{Mn}(\mathrm{dca})_{3}\right]$ and [TPnA] $\left[\mathrm{Mn}(\mathrm{dca})_{3}\right]$ from $34^{\circ} \mathrm{C}$ to $258^{\circ} \mathrm{C}$ (i.e. below $T_{\mathrm{d}}$ in each case) to determine changes in local structure.

The structure factors, $F(Q)$, of [ $\mathrm{TBuA}]\left[\mathrm{Mn}(\mathrm{dca})_{3}\right]$ cease to contain sharp features above $190{ }^{\circ} \mathrm{C}$, indicating the loss of long-range crystalline order at this temperature (Fig. 4a, complete dataset shown in Fig. S11a). This temperature coincides with the $T_{\mathrm{m}}$ observed in DSC experiments $\left(T_{\mathrm{m} \text {-onset }}=185^{\circ} \mathrm{C}\right)$. No further significant changes in the $F(Q)$ s occurred until the maximum temperature of $258{ }^{\circ} \mathrm{C}$ reached in the experiment. A similar experiment for $[\mathrm{TPnA}]\left[\mathrm{Mn}(\mathrm{dca})_{3}\right]$ demonstrated a loss of sharp features from the $F(Q)$ at $169^{\circ} \mathrm{C}$, which again agrees with the DSC experiments ( $T_{\mathrm{m} \text {-onset }}$ $\left.=149^{\circ} \mathrm{C}\right)$ (Fig. S12a).

The $F(Q) s$ for both samples collected after cooling back to room temperature from the last experimental temperature $\left(258{ }^{\circ} \mathrm{C}\right)$ provided evidence of recrystallization back to the original structure in each case (Fig. S11a, S12a).

Pair distribution functions (PDF), $D(r) \mathrm{s}$, were extracted from the $F(Q) s$ after appropriate data corrections using experimental pycnometric densities (Table S5). ${ }^{33}$ The variable temperature PDFs of [TBuA][Mn(dca) ${ }_{3}$ (Fig. 4b, full dataset in Fig. S11b) demonstrate a reduction in the strength of the peaks and troughs above $10 \AA$ at 190 ${ }^{\circ} \mathrm{C}$, consistent with liquid-like atom-atom correlations above the framework $T_{\mathrm{m}}$. No further substantial changes were observed, up to the maximum temperature of the experiment at $258^{\circ} \mathrm{C}$. A similar scenario is observed in the PDFs of [TPnA] $\left[\mathrm{Mn}(\mathrm{dca})_{3}\right]$ (Fig. S12b), with the disappearance of strong peaks in the correlations above $10 \AA$ at temperatures above the $T_{\mathrm{m}}$ observed in DSC measurements.

To evaluate the specific atom-atom pair correlations to the PDF peaks, the published structure for the $[\mathrm{TBuA}]\left[\mathrm{Mn}(\mathrm{dca})_{3}\right]$ crystalline sample was refined against the PDF data (Methods, Fig. S13). ${ }^{30,34}$ The weighted partial PDFs, $g(r)$, were then calculated from the refined structure, and show that the $\mathrm{Mn}-\mathrm{N}$ correlation at ca. $2.22 \AA$ is accompanied by small contributions from nearby $\mathrm{C}-\mathrm{C}$ and $\mathrm{C}-\mathrm{N}$ correlations at $2.45 \AA$ and $2.57 \AA$ respectively (Fig. S14).

The position, full-width at half-maximum (FWHM) and area of the $\mathrm{C}-\mathrm{C}, \mathrm{C}-\mathrm{N}$ and $\mathrm{Mn}-\mathrm{N}$ correlations were fitted using a Gaussian 


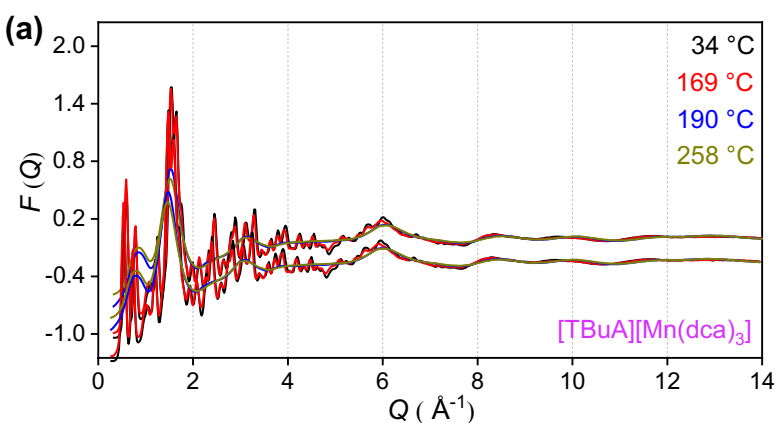

(b)

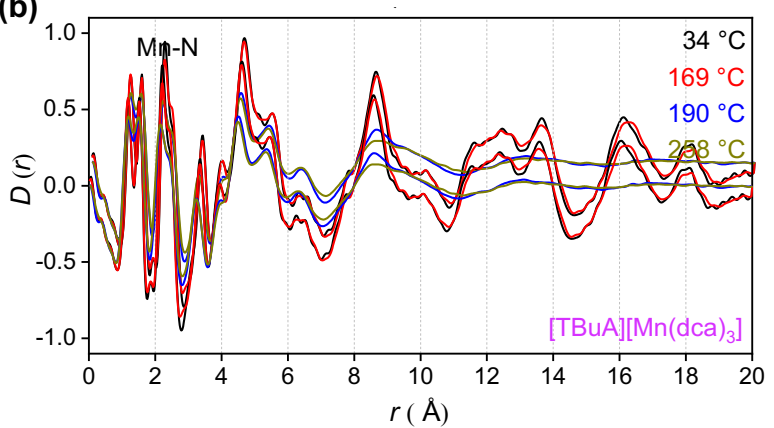

Figure. 4 (a) X-ray structure factors, $F(Q)$ and (b) Pair distribution functions (PDF), $D(r)$ for [TBuA] $\left[\mathrm{Mn}(\mathrm{dca})_{3}\right]$ upon heating. Only selected temperatures are shown for clarity, see Fig. $\mathbf{S 1 1}$ for full data.

function. The proximity of the C-C $(2.45 \AA)$ and $\mathrm{C}-\mathrm{N}(2.57 \AA)$ correlations to that for $\mathrm{Mn}-\mathrm{N}(2.22 \AA)$, rendered it necessary to fit the experimental peak using multiple peak fitting. Regression analysis is shown in Fig. S15 and the extracted parameters are tabulated in Table S6. The substantial contribution of instrumental broadening to the peaks $\left(2 \pi / Q_{\max }=0.29 \AA\right)$ dominates the measurements, and, combined with correlations in the fitting parameters from overlapping peaks, direct links to the Lindemann criterion for melting could not be made. ${ }^{35}$

Nevertheless, the temperature variation of the FWHM, peak positions and areas at the melting point clearly show marked changes, which may be consistent with a melting process involving $\mathrm{Mn}-\mathrm{N}$ bond breakage and some thermal decomposition of both organic species (Fig. S16). A similar analysis for [TPnA][Mn(dca $\left.)_{3}\right]$ (Fig. S17 - S20) was carried out and is also suggestive of changes at $T_{\mathrm{m}}$.

\section{Linking Melting Temperature with Tolerance factor}

The stability of perovskite structures has been extensively discussed, using values of the Tolerance Factor $(\alpha=$ $\left(r_{\mathrm{A}}+r_{\mathrm{X}}\right) / \sqrt{2}\left(r_{\mathrm{B}}+r_{\mathrm{X}}\right)$, where $r_{\mathrm{A}}, r_{\mathrm{B}}, r_{\mathrm{X}}$ are the ionic radii of ' $\mathrm{A}$ ' cation, ' $\mathrm{B}$ ' metal and ' $\mathrm{X}$ ' anion, respectively) proposed by Goldschmidt in 1926 for inorganic perovskites. ${ }^{29}$ Intense research has focused on using this relatively simple relation, which relies upon maximizing enthalpic interactions in the structure to predict whether a given chemical composition will form a cubic $(0.8<\alpha<1)$ or a distorted structure. Cheetham and co-workers have modified this relation, basing this on a rigid sphere model which treats highly anisotropic anions e.g. $\mathrm{HCOO}^{-}, \mathrm{N}_{3}{ }^{-}, \mathrm{CN}-\mathrm{N}(\mathrm{CN})_{2}$ as rigid cylinders, with effective radius $r_{\text {Xeff }}$ and an effective height $h_{\text {Xeff }}$ for HOIPs (eqn. 2). ${ }^{36}$

$$
\alpha=\left(r_{\text {Aeff }}+r_{\text {Xeff }}\right) / \sqrt{2}\left(r_{\mathrm{B}}+0.5 h_{\text {Xeff }}\right)
$$

where, $r_{\text {Aeff }}=r_{\text {mass }}+r_{\text {ion }}$, with $r_{\text {mass }}$ being the distance between the centre of mass of the molecule and the atom with the largest distance to the centre of mass (excluding hydrogen atoms), and $r_{\text {ion }}$ is the corresponding ionic radius of this atom.

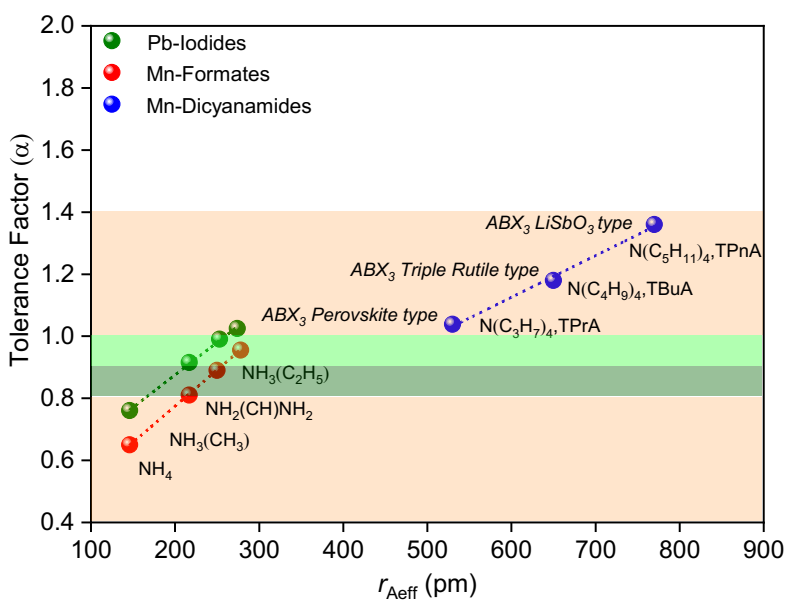

Figure. 5 Values of effective radius of tetraalkylammonium cations is plotted with the calculated values of tolerance factor $(\alpha)$ for various $A B X_{3}$ perovskite and polymorphic hybrid structures. The data for the current $A B X_{3}$ perovskite and polymorphic $\mathrm{Mn}$-dicyanamide structures (blue points) is shown here along with other $\mathrm{ABX}_{3}$ materials, ${ }^{36}$ e.g. Mn-Formate (red data point) and $\mathrm{Pb}$ lodide (green data point). The light green and dark green shaded area ( $\alpha=0.8$ - 1.0) highlights the range highlighted by Cheetham et al, where perovskite and distorted perovskite structures are formed. Outside of this range (1.0 $>\alpha$ $>0.8$, pink) indicates unstable and low symmetry structures.

Cheetham et al found, using their adjusted relationship, that although cubic perovskites were still typically found in the region $0.9-1.0$, values of $0.8-0.9$ led to distorted perovskite structures, and those less than 0.8 generally led to other architectures such as ilmenite. On the other hand, values larger than 1.0 were observed to yield many hexagonal structures.

The size of the A site cation in the dca-based materials studied here compared to those in known hybrid halides and formates, results in larger tolerance factors between 1.0 and 1.4 (Fig. 5), with these increasing upon increasing organic cation size (1.03 $( \pm 0.002)$ for $[\operatorname{TPrA}]\left[\mathrm{Mn}(\mathrm{dca})_{3}\right], 1.18( \pm 0.003)$ for $[\mathrm{TBuA}]\left[\mathrm{Mn}(\mathrm{dca})_{3}\right], 1.36( \pm$ $0.005)$ for $\left.[\mathrm{TPnA}]\left[\mathrm{Mn}(\mathrm{dca})_{3}\right]\right)$. The reduction in $T_{\mathrm{m}}$ is therefore linked to a weakening in interactions between the constituent components. A similar argument may be made for the variation in ' $B$ ' metal from $\mathrm{Mn} \rightarrow \mathrm{Fe} \rightarrow \mathrm{Co}$, which increases the Tolerance values slightly (e.g. 1.03 $( \pm 0.002)$ for $[\operatorname{TPrA}]\left[\mathrm{Mn}(\mathrm{dca})_{3}\right], 1.05( \pm 0.004)$ for $[\operatorname{TPrA}]\left[\mathrm{Fe}(\mathrm{dca})_{3}\right]$, $1.07( \pm 0.004)$ for $[\mathrm{TPrA}]\left[\mathrm{Co}(\mathrm{dca})_{3}\right]$, Fig. S21; calculated using the values of constituent ions sizes in the structures presented by Garcia et. al $\left.{ }^{17,19}\right)$. This is again linked to a successive reduction in $T_{\mathrm{m}}$.

\section{Glass Formation}

As in our previous report on $a_{\mathrm{g}}[\operatorname{TPrA}]\left[\mathrm{M}(\mathrm{dca})_{3}\right]$ samples, ${ }^{22}$ opaque, glass-like pieces were observed after cooling the melts from their offset of melting near $T_{\mathrm{d}}$ (Insets of Fig. 6a-e), and found to be amorphous by X-ray diffraction (Figs. S22 and S23). The glasses, in keeping with existing nomenclature on hybrid glasses, are thus termed $a_{\mathrm{g}}[\mathrm{TAIA}]\left[\mathrm{M}(\mathrm{dca})_{3}\right]$ ( $a_{\mathrm{g}}$ : melt-quenched amorphous).

The glass transition temperatures $\left(T_{\mathrm{g}}\right)$ of all $a_{\mathrm{g}}[\mathrm{TBuA}]\left[\mathrm{M}(\mathrm{dca})_{3}\right]$ and $a_{\mathrm{g}}[\mathrm{TPnA}]\left[\mathrm{M}(\mathrm{dca})_{3}\right](\mathrm{M}=\mathrm{Mn}, \mathrm{Fe}, \mathrm{Co})$ melt-quenched glasses were obtained in DSC experiments each case (Fig. 6). Complete cycles of heating-cooling-heating runs are shown in the supporting information (Fig. S24-29). The low values of $T_{\mathrm{g}}\left(33^{\circ} \mathrm{C}--26^{\circ} \mathrm{C}\right)$, are 
(a)
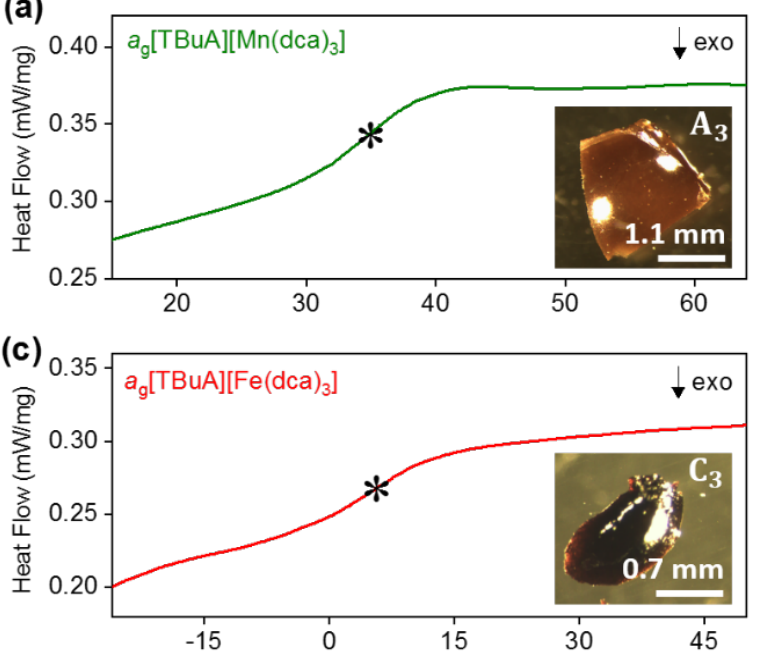

(e)

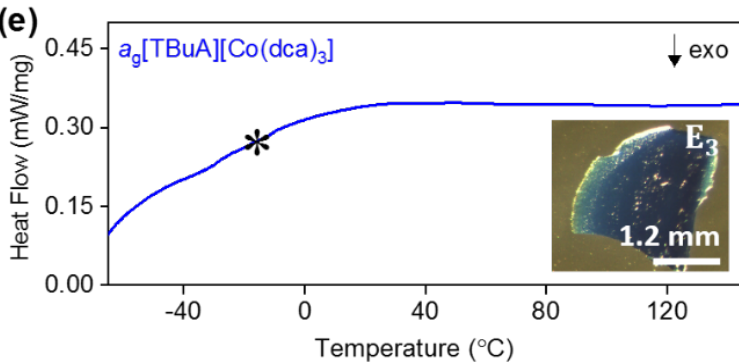

(b)

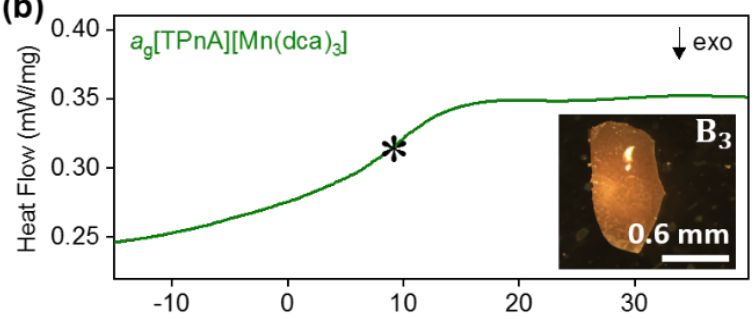

(d)
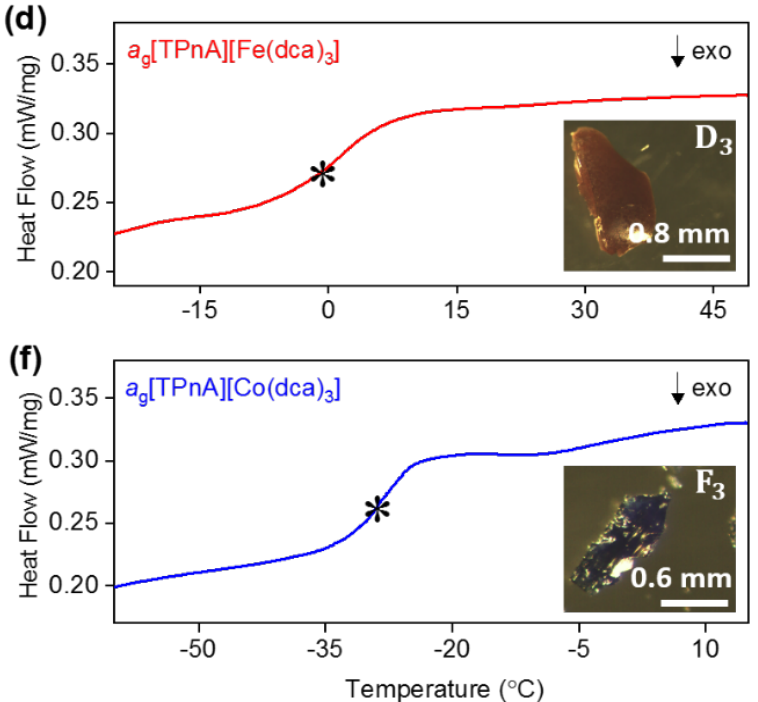

Figure. 6 Change in heat flow as a function of temperature for (a) $a_{\mathrm{g}}[\mathrm{TBuA}]\left[\mathrm{Mn}(\mathrm{dca})_{3}\right],(\mathbf{b}) a_{\mathrm{g}}[\mathrm{TPnA}]\left[\mathrm{Mn}(\mathrm{dca})_{3}\right],(\mathbf{c}) a_{\mathrm{g}}[\mathrm{TBuA}]\left[\mathrm{Fe}(\mathrm{dca})_{3}\right],(\mathrm{d}) a_{\mathrm{g}}[\mathrm{TPnA}]\left[\mathrm{Fe}(\mathrm{dca})_{3}\right]$, (e) $a_{\mathrm{g}}[\mathrm{TBuA}]\left[\mathrm{Co}(\mathrm{dca})_{3}\right],(\mathbf{f}) a_{\mathrm{g}}[\mathrm{TPnA}]\left[\mathrm{Co}(\mathrm{dca})_{3}\right]$. Onset of glass transitions $\left(T_{\mathrm{g}}\right)$ were evaluated and marked with asterisk. Full temperature scans were shown in supporting information. Inset shows the optical images of each glasses. All experiments performed in an Argon atmosphere.

broadly consistent with both their low $T_{\mathrm{m}}$ values $\left(185^{\circ} \mathrm{C}-106^{\circ} \mathrm{C}\right)$,

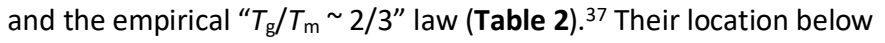
room temperature is similar to the behaviour of dca based ILs, which generally exhibit glass transitions below room temperature (e.g. -67 ${ }^{\circ} \mathrm{C}$ for $\left.\left[\mathrm{N}_{8444}\right][\mathrm{dca}]\right) \cdot{ }^{38,39}$

Table 2. Properties of glass transitions in melt-quenched $a_{\mathrm{g}}[\mathrm{TAI} \mathrm{A}]\left[\mathrm{M}(\mathrm{dca})_{3}\right]$.

\begin{tabular}{|clll|}
\hline Samples & $T_{\mathrm{g}}\left(^{\circ} \mathrm{C}\right)$ & $T_{\mathrm{g}} / \boldsymbol{T}_{\mathrm{m}}{ }^{\mathbf{b}}$ & Ref \\
$a_{\mathrm{g}}[\mathrm{TPrA}]\left[\mathrm{Mn}(\mathrm{dca})_{3}\right]^{\mathrm{a}}$ & 223 & 0.89 & 22 \\
$a_{\mathrm{g}}[\mathrm{TPrA}]\left[\mathrm{Fe}(\mathrm{dca})_{3}\right]^{\mathrm{a}}$ & 225 & 0.90 & 22 \\
$a_{\mathrm{g}}[\mathrm{TPrA}]\left[\mathrm{Co}(\mathrm{dca})_{3}\right]^{\mathrm{a}}$ & 125 & 0.82 & 22 \\
$a_{\mathrm{g}}[\mathrm{TBuA}]\left[\mathrm{Mn}(\mathrm{dca})_{3}\right]$ & 33 & 0.66 & This work \\
$a_{\mathrm{g}}[\mathrm{TBuA}]\left[\mathrm{Fe}(\mathrm{dca})_{3}\right]$ & 6 & 0.62 & This work \\
$a_{\mathrm{g}}[\mathrm{TBuA}]\left[\mathrm{Co}(\mathrm{dca})_{3}\right]$ & -12 & 0.63 & This work \\
$a_{\mathrm{g}}[\mathrm{TPnA}]\left[\mathrm{Mn}(\mathrm{dca})_{3}\right]$ & 9 & 0.66 & This work \\
$a_{\mathrm{g}}[\mathrm{TPnA}]\left[\mathrm{Fe}(\mathrm{dca})_{3}\right]$ & -1 & 0.66 & This work \\
$a_{\mathrm{g}}[\mathrm{TPnA}]\left[\mathrm{Co}(\mathrm{dca})_{3}\right]$ & -26 & 0.65 & This work \\
\hline
\end{tabular}

a The values were taken from our previous report. ${ }^{22}$ b Ratio of $T_{\mathrm{g}} / T_{\mathrm{m}}$ is calculated from temperatures in Kelvin.

These results are consistent with the observation that $a_{\mathrm{g}}[\mathrm{TPnA}]\left[\mathrm{Fe}(\mathrm{dca})_{3}\right]$ and $a_{\mathrm{g}}[\mathrm{TPnA}]\left[\mathrm{Co}(\mathrm{dca})_{3}\right]$ remain viscous after quenching at room temperature and take a relatively long time to solidify (see Methods). This same phenomenon also explains why these melts in particular appear prone to partial recrystallization after cooling from offset of $T_{\mathrm{m}}$ (Fig. S30).
Perhaps counter intuitively, heating these structures near to $T_{\mathrm{d}}$ and the use of slower cooling rates prevented recrystallization in $a_{\mathrm{g}}[\mathrm{TBuA}]\left[\mathrm{M}(\mathrm{dca})_{3}\right]$ and $a_{\mathrm{g}}[\mathrm{TPnA}]\left[\mathrm{M}(\mathrm{dca})_{3}\right]^{22}$ Minimal gravimetric mass loss ( $2.0 \%$ ) was detected upon quenching the melts at ca. 10 ${ }^{\circ} \mathrm{C}$ min $^{-1}$ near to room temperature (Figs. S31 and S32). However, a slightly higher mass loss ( $5.0 \%$ ) was detected during quenching at slow cooling rates (Fig. S33), which would be consistent with some degree of ligand decomposition. This is reflected in the FT-IR spectra of the glasses which combines of two (weak) new bands at 1629$1634 \mathrm{~cm}^{-1}$ and $802-806 \mathrm{~cm}^{-1}$ as reported previously (Fig. S34). ${ }^{22,40-42}$

The behaviour is very similar to dca-based organic-inorganic salts, which possess ionic liquid (IL) character at room temperature. ${ }^{38,39}$ MacFarlane et al showed that, for alkylpyrrolidinium-dca based ILs, the increase in alkyl chain length in pyrrolidinium organic cations e.g. from $\left[\mathrm{P}_{13}\right][\mathrm{dca}]$ to $\left[\mathrm{P}_{16}\right][\mathrm{dca}]$ (where $\mathrm{P}_{13}=\mathrm{N}$-propyl-N-methylpyrrolidinium, $\quad \mathrm{P}_{16}=\mathrm{N}$-hexyl- $\mathrm{N}$ methylpyrrolidinium) increases the entropy of melting $\left(\Delta S_{f}=5 \mathrm{~J} \mathrm{~mol}^{-}\right.$ ${ }^{1} \mathrm{~K}^{-1}$ for $\left[\mathrm{P}_{13}\right][\mathrm{dca}], 95 \mathrm{~J} \mathrm{~mol}^{-1} \mathrm{~K}^{-1}$ for $\left.\left[\mathrm{P}_{16}\right][\mathrm{dca}]\right) .{ }^{39}$ They also showed a decrease in viscosity from 50 to $45 \mathrm{cP}$ (at $20^{\circ} \mathrm{C}$ ) with increase in cation chain length from $\left[\mathrm{P}_{14}\right][\mathrm{dca}]$ to $\left[\mathrm{P}_{16}\right][\mathrm{dca}]$ (where $\mathrm{P}_{14}=\mathrm{N}$-butyl$\mathrm{N}$-methylpyrrolidinium). The $\mathrm{ABX}_{3}$ structures studied here behave in the same way, in which the increase in alkyl chain length (steric effect) in A-site organic cation from $a_{\mathrm{g}}[\operatorname{TPrA}]\left[\mathrm{M}(\mathrm{dca})_{3}\right]$ to $a_{\mathrm{g}}[\mathrm{TPnA}]\left[\mathrm{M}(\mathrm{dca})_{3}\right]$ is offset by the larger entropy of melting (e.g. $\Delta S_{\mathrm{f}}$ $=95 \mathrm{~J} \mathrm{~mol}^{-1} \mathrm{~K}^{-1}$ for $a_{\mathrm{g}}[\mathrm{TPrA}]\left[\mathrm{Fe}(\mathrm{dca})_{3}\right], 149 \mathrm{~J} \mathrm{~mol}^{-1} \mathrm{~K}^{-1}$ for $\left.a_{\mathrm{g}}[\mathrm{TPnA}]\left[\mathrm{Fe}(\mathrm{dca})_{3}\right]\right)$ (Fig. 3), and hence accounts for the less viscous character in TPnA containing $\mathrm{ABX}_{3}$ structures at room temperature. 

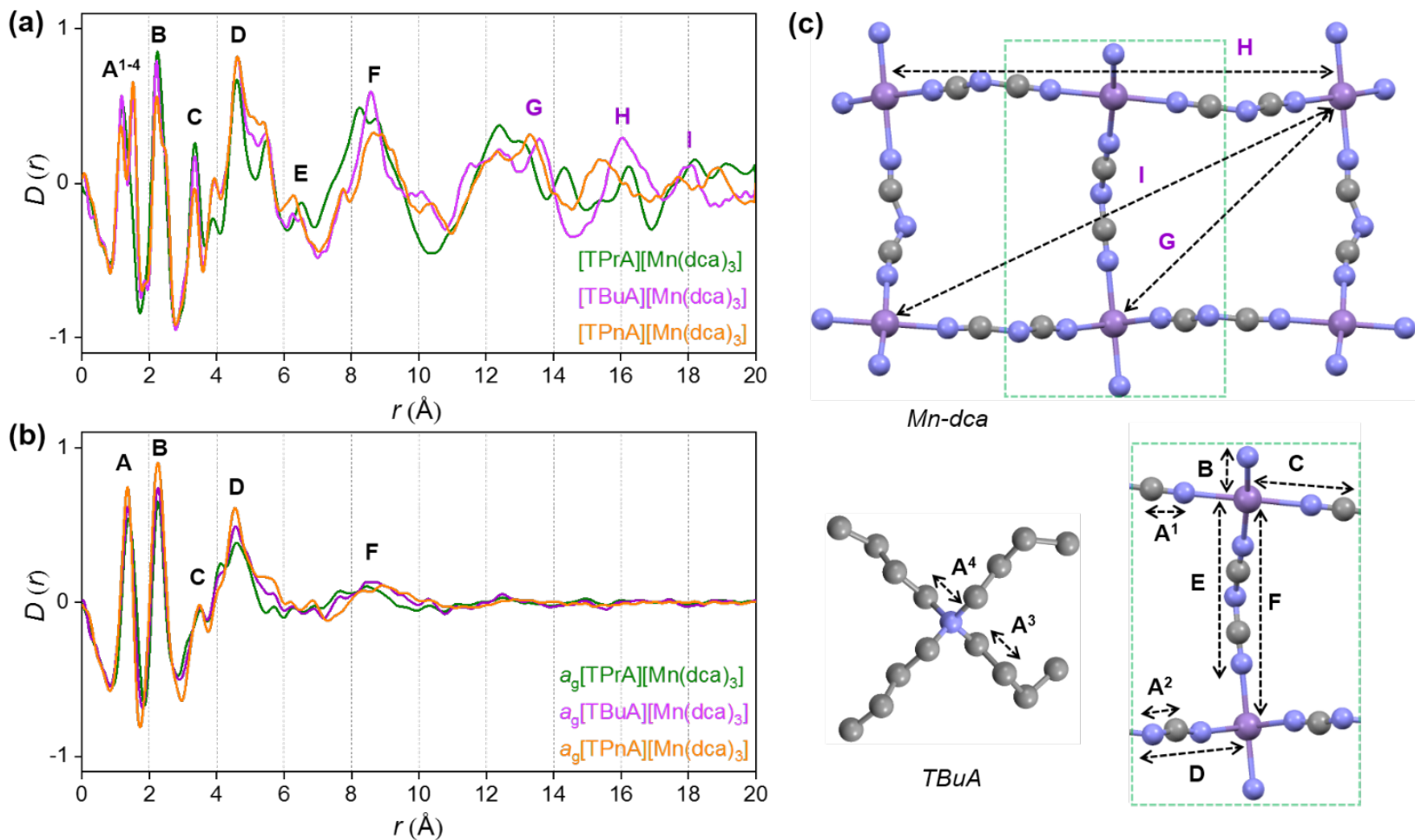

Figure. 7 Pair distribution functions for $[\operatorname{TPrA}]\left[\mathrm{Mn}(\mathrm{dca})_{3}\right]_{, 2}^{22}[\mathrm{TBuA}]\left[\mathrm{Mn}(\mathrm{dca})_{3}\right]$ and $[\operatorname{TPn} A]\left[\mathrm{Mn}(\mathrm{dca})_{3}\right]$ (a) crystals and (b) glasses at room temperature, with the atom pairs that contribute most of the intensity in the labelled peaks indicated inside the (c) dotted structural fragment (A-F) of [TBuA][Mn(dca) $\left.{ }_{3}\right]$ for PDF peak assignment using the published cif at $298 \mathrm{~K}^{30}$ (Violet: Mn; Grey: C; Blue: N; H atoms omitted for clarity.

\section{X-ray Structural Characterisation - PDF Analysis}

Ex-situ, room temperature PDF data were also collected on the three $[\mathrm{TAIA}]\left[\mathrm{Mn}(\mathrm{dca})_{3}\right]\left(\mathrm{TAIA}=\mathrm{TPrA},{ }^{22} \mathrm{TBuA}, \mathrm{TPnA}\right)$ samples (Fig. 7a), and the calculated partial pair distributions functions were used to aid feature assignment (Figs. S13-18). Short range correlations (up to 10 $\AA$ ) are ascribed to those between atoms present in a single Mn-dcaMn linkage (i.e. green bounded portion of Fig. 7c) and those between atoms within A-site molecules, which are largely invariant in position upon increasing the size of the A cation. Specifically, the correlation noted at $r=\sim 1.1-1.3 \AA$, contains contributions from $\mathrm{C}-\mathrm{C}, \mathrm{C}-\mathrm{N}$ (including $\mathrm{C} \equiv \mathrm{N}$ ) atom pairs $\left(\overleftrightarrow{\mathrm{A}^{1}}, \overleftrightarrow{\mathrm{A}}^{2}, \overleftrightarrow{\mathrm{A}}^{3}, \overleftrightarrow{\mathrm{A}^{4}}\right)$. The correlation at $r=2.25$ $\AA$ is ascribed to the $\mathrm{Mn}-\mathrm{N}$ pair $(\overleftrightarrow{\mathrm{B}})$ and the two peaks at $3.3 \AA$ and 4.7 $\AA$ are ascribed to the $\mathrm{Mn}-\mathrm{N}-\mathrm{C}(\stackrel{\mathrm{C}}{)})$ and $\mathrm{Mn}-\mathrm{N}-\mathrm{C}-\mathrm{N}(\overleftrightarrow{\mathrm{D}})$ correlations respectively. The major contributions to the peak at $r=\sim 8.2 \AA(\overleftrightarrow{\mathrm{F}})$ arise primarily from the $\mathrm{Mn}-\mathrm{Mn}$ correlation.

Correlations at high-r (>10 $\mathrm{\AA}$ ) are dominated by those between atoms in adjacent $\mathrm{Mn}$-dca pairs $(\overleftrightarrow{\mathrm{G}}-\overleftrightarrow{\mathrm{I}})$, and as such are more heavily influenced by the increase in A cation size. As expected, changes in the $B$ site metal appeared to have negligible effect on the observed correlations (Fig. S35).

The local structures of vitrified $a_{\mathrm{g}}[\mathrm{TBuA}]\left[\mathrm{Mn}(\mathrm{dca})_{3}\right]$ and $a_{\mathrm{g}}[\mathrm{TPnA}]\left[\mathrm{Mn}(\mathrm{dca})_{3}\right]$ were probed by using samples prepared in the SDT and DSC experiments (see Methods). The resultant $F(Q) s$ did not contain any Bragg scattering (Fig. S36a and Fig. S37a), confirming their amorphous nature (Fig. S36a-c).

We found similar results for $a_{\mathrm{g}}[\mathrm{TBuA}]\left[\mathrm{Fe}(\mathrm{dca})_{3}\right]$ and $a_{\mathrm{g}}[\mathrm{TBuA}]\left[\mathrm{Co}(\mathrm{dca})_{3}\right]$ materials (Fig. S36). The short-range correlations $(\overleftrightarrow{\mathrm{A}}-\stackrel{\leftrightarrow}{\mathrm{F}})$ present in the glass samples were relatively similar to the crystalline precursors (Fig. 7b, Fig. S36e-f). Correlations belonging to
$\mathrm{Mn}-\mathrm{N}-\mathrm{C}(\stackrel{\leftrightarrow}{\mathrm{C}})$ and $\mathrm{Mn}-\mathrm{N}-\mathrm{C}-\mathrm{N}(\stackrel{\leftrightarrow}{\mathrm{D}})$ were however reduced in intensity and substantially broadened. Prominent correlations were also not observed beyond $10 \AA$, consistent with the mechanism of melting involving the breakage of $\mathrm{M}-\mathrm{N}$ bonds, and the associated movement of the A site cation out of the central cavity. ${ }^{22}$

Difficulties in preparing a sufficient quantity of finely ground solid samples for PDF measurements of $a_{\mathrm{g}}[\mathrm{TPnA}]\left[\mathrm{Fe}(\mathrm{dca})_{3}\right]$ and $a_{\mathrm{g}}[\mathrm{TPnA}]\left[\mathrm{Co}(\mathrm{dca})_{3}\right]$ (owing to their viscous melts), led us to obtain variable temperature PDF data for these two compounds. Data collected in the liquid state for each bore a strong resemblance to those for other glass samples in this study, maintaining the same correlations as preheated material and with a similar behavior to their homologous $a_{\mathrm{g}}[\mathrm{TPnA}]\left[\mathrm{Mn}(\mathrm{dca})_{3}\right]$ (Fig. S37e-f).

\section{Magnetic Study}

Temperature dependent DC magnetic susceptibility measurements were carried out for all crystalline and melt-quenched glass samples, and the variation of effective magnetic moment, $\mu_{\text {eff }}$ (calculated from $\chi_{\mathrm{M}}$ : molar magnetic susceptibility, $\mu$ (B.M.) $=2.83 \sqrt{ } \chi_{\mathrm{M}} \mathrm{T}$ ) is plotted as a function of $T$ in Fig. $\mathbf{S 3 8} \mathbf{- S 4 0 .}{ }^{43-47}$ Room temperature magnetic moments $\left(\mu_{\mathrm{RT}}\right)$ for all crystalline phases are as per the number of unpaired spins present in their high spin ' $d$ ' orbital configurations. The decrease at low temperatures in all cases demonstrates a contribution of zero-field splitting and a weak antiferromagnetic coupling. ${ }^{28}$ Interestingly, the $\mu_{\mathrm{RT}}$ for the glasses were found to be slightly lower than those for the corresponding crystalline phases, indicating a reduction in oxidation state for a proportion of metal centres during melt-quenching $\left(\mathrm{M}^{2+} \rightarrow \mathrm{M}^{0}\right)$. These differences were used to calculate the percentage of metal ions reduced in each case $\left(a_{\mathrm{g}}[\mathrm{TBuA}]\left[\mathrm{Mn}(\mathrm{dca})_{3}\right]-1.7 \%, a_{\mathrm{g}}[\mathrm{TPnA}]\left[\mathrm{Mn}(\mathrm{dca})_{3}\right]-0.5 \%\right.$, $a_{\mathrm{g}}[\mathrm{TBuA}]\left[\mathrm{Fe}(\mathrm{dca})_{3}\right]-3.9 \%, a_{\mathrm{g}}[\mathrm{TPnA}]\left[\mathrm{Fe}(\mathrm{dca})_{3}\right]-4.5 \%$, $\left.a_{\mathrm{g}}[\mathrm{TBuA}]\left[\mathrm{Co}(\mathrm{dca})_{3}\right]-2.0 \%, a_{\mathrm{g}}[\mathrm{TPnA}]\left[\mathrm{Co}(\mathrm{dca})_{3}\right]-2.8 \%\right) .{ }^{20}$ These are 
lower than the reduction observed in the $a_{\mathrm{g}}[\operatorname{TPrA}]\left[\mathrm{Mn}(\mathrm{dca})_{3}\right]$ series, which is consistent with their lower $T_{\mathrm{m}} \mathrm{s}$ and wider temperature range between $T_{\mathrm{m}}$ and $T_{\mathrm{d}}$. Elemental compositions of both crystalline and glassy states were also similar (Table S7).

\section{Conclusions}

The results reported in this work demonstrate the effect of chemical composition and structure type on the melting temperature of $\mathrm{ABX}_{3}$ hybrid organic-inorganic materials. Specifically, the comparison of four novel [TAIA][M(dca $)_{3}$ ] structures with 5 known materials facilitated a study of the relationship of thermal properties to chemical structure. The size of A-site alkylammonium cation and Bsite transition metal was altered and found to influence $T_{\mathrm{m}}$. In particular, increasing the size of the A-site cation from TPrA $\rightarrow$ TBuA $\rightarrow$ TPnA was observed to result in an increase in Tolerance Factor, and decrease in melting temperature through an increase in the entropy of fusion.

The majority of the melts formed were found to recrystallize partially upon cooling from temperatures (near their $T_{\text {m-offset }}$ ). To form the glasses, annealing near their $T_{\mathrm{d}}$ was necessary, which suggests a small degree of decomposition of the organic linker occurs. Those structures possessing bulkier TPnA A-site cations remained viscous after quenching at room temperature, and solidified only after several days. The viscous character of $a_{\mathrm{g}}[\mathrm{TPnA}]\left[\mathrm{Fe}(\mathrm{dca})_{3}\right]$ and $a_{\mathrm{g}}[\mathrm{TPnA}]\left[\mathrm{Co}(\mathrm{dca})_{3}\right]$ is linked to their high $\Delta S_{\mathrm{f}}$ values upon melting and below-room temperature $T_{\mathrm{g}} \mathrm{s}$. Alongside relatively low values of $T_{\mathrm{g}}$ below room temperature indicates the kinematic similarity of this dca based $\mathrm{ABX}_{3}$ melts with dca based ionic liquids. Such basic observations may provide further rules for the design of glass forming hybrid structures.

Previously, we have shown that the glasses formed via meltquenching HOIPs possess potential as thermoelectric materials, owing to their moderate electrical conductivity as well as very low thermal conductivity values. This study provides a rational for altering the physical properties of the starting perovskite and nonperovskite type $\mathrm{ABX}_{3}$ materials, and at the same time opens up directions in forming further examples of functional liquid and glasses from $\mathrm{ABX}_{3}$ hybrid structures.

\section{Author Contributions}

B.K.S. and T.D.B. designed the project. C.C.B. and M.L.R.G. collected and analysed the single crystal $X$-ray diffraction data. T.D.B., A. F. S., M. F. T., L.N.M., D. K., T. F., P. A. C. and M. D. L. collected the X-ray total scattering data. B.K.S, D.A.K. and T.D.B. analysed the data. B.K.S. performed and analysed all other experimental data. B.K.S. and T.D.B. wrote the manuscript with input from all authors.

\section{Conflicts of interest}

There are no conflicts to declare.

\section{Acknowledgements}

B.K.S. thanks the Royal Society and the Science and Engineering Research Board of India (SERB) for their combined support in Newton
International Fellowship (NIF\R1\180163). C.C.B. acknowledges the European Social Funds and the Regional Government of Madrid for a postdoctoral contract (PEJD-2018-POST/IND-7909). T.D.B. thanks the Royal Society for a University Research Fellowship (UF150021) and a research grant (RG94426), the University of Canterbury Te Whare Wānanga o Waitaha, New Zealand, for a University of Cambridge Visiting Canterbury Fellowship and the Leverhulme Trust for a Philip Leverhulme Prize (2019). T.D.B. and C.C.B. also gratefully acknowledge that the work was funded by a Leverhulme Trust Research Project Grant (RPG-2020-005). We acknowledge the provision of synchrotron access to Beamline I15-1 (EE20038) at the Diamond Light Source. M.F.T would like to thank Corning Incorporated for project funding. The authors acknowledge A. Sapnik (University of Cambridge) for useful discussions and data collection.

\section{Experimental Methods}

\section{Thermal analysis}

Simultaneous thermogravimetric and calorimetric analysis (TGA/Heat flow) were carried out in a SDT apparatus (TA Q600). Data were collected in the range from $25^{\circ} \mathrm{C}$ to $400^{\circ} \mathrm{C}$ at a scan rate of 10 ${ }^{\circ} \mathrm{C}$ min $^{-1}$ under an Argon atmosphere.

To obtain the liquid states, samples ( $10 \mathrm{mg}$ ) were placed into a $70 \mu \mathrm{L}$ Alumina crucible and heated above their respective melting offsets at a heating rate of $10{ }^{\circ} \mathrm{C} \mathrm{min}^{-1}$ in SDT TA Q600 under Argon atmosphere. Differential Scanning Calorimetry (DSC) measurements were conducted using a TA Q2000 instrument. To obtain the glass transitions, the samples were reheated after cooling to low temperatures.

\section{Preparation of glasses}

$a_{\mathrm{g}}[\mathrm{TBuA}]\left[\mathrm{Mn}(\mathrm{dca})_{3}\right]:$ The $[\mathrm{TBuA}]\left[\mathrm{Mn}(\mathrm{dca})_{3}\right]$ crystal was heated at 10 ${ }^{\circ} \mathrm{C}$ min $^{-1}$ to $280^{\circ} \mathrm{C}$, then cooled under an Argon atmosphere (flow rate $50 \mathrm{ml} \mathrm{min}^{-1}$ ) to $-20^{\circ} \mathrm{C}$ at $\mathrm{ca} .3^{\circ} \mathrm{C} \mathrm{min}^{-1}$.

$a_{\mathrm{g}}[\mathrm{TPnA}]\left[\mathrm{Mn}(\mathrm{dca})_{3}\right]:$ The $[\mathrm{TPnA}]\left[\mathrm{Mn}(\mathrm{dca})_{3}\right]$ crystal was heated at 10 ${ }^{\circ} \mathrm{C}$ min $^{-1}$ to $282^{\circ} \mathrm{C}$, then cooled under an Argon atmosphere (flow rate $50 \mathrm{ml} \mathrm{min}-1)$ to $-50{ }^{\circ} \mathrm{C}$ at ca. $3^{\circ} \mathrm{C} \mathrm{min}^{-1}$.

$a_{\mathrm{g}}[\mathrm{TBuA}]\left[\mathrm{Fe}(\mathrm{dca})_{3}\right]:$ The $[\mathrm{TBuA}]\left[\mathrm{Fe}(\mathrm{dca})_{3}\right]$ crystal was heated at $10^{\circ} \mathrm{C}$ $\mathrm{min}^{-1}$ to $265^{\circ} \mathrm{C}$, then cooled under an Argon atmosphere (flow rate $50 \mathrm{ml} \mathrm{min}-1$ ) to $-50{ }^{\circ} \mathrm{C}$ at $\mathrm{ca} .5^{\circ} \mathrm{C} \mathrm{min}-1$.

$a_{\mathrm{g}}[\mathrm{TPnA}]\left[\mathrm{Fe}(\mathrm{dca})_{3}\right]:$ The $[\mathrm{TPnA}]\left[\mathrm{Fe}(\mathrm{dca})_{3}\right]$ crystal was heated at $10{ }^{\circ} \mathrm{C}$ $\mathrm{min}^{-1}$ to $265^{\circ} \mathrm{C}$, then cooled under an Argon atmosphere (flow rate $50 \mathrm{ml} \mathrm{min}^{-1}$ ) to $-70{ }^{\circ} \mathrm{C}$ at $\mathrm{ca} .5^{\circ} \mathrm{C} \mathrm{min}-1$. The semi-solid (viscous) melt formed after was kept for 72 hours at room temperature to get densified (Note: Solidification of the viscous sample at room temperature might result in partial recrystallization and so successive heating may require to remove the remnant crystallisation and achieve X-ray amorphous samples, Fig. S23b).

$a_{\mathrm{g}}[\mathrm{TBuA}]\left[\mathrm{Co}(\mathrm{dca})_{3}\right]:$ The $[\mathrm{TBuA}]\left[\mathrm{Co}(\mathrm{dca})_{3}\right]$ crystal was heated at $10^{\circ} \mathrm{C}$ $\mathrm{min}^{-1}$ to $255^{\circ} \mathrm{C}$, then cooled under an Argon atmosphere (flow rate $50 \mathrm{ml} \mathrm{min}^{-1}$ ) to $-70^{\circ} \mathrm{C}$ at $c a .5^{\circ} \mathrm{C} \mathrm{min}^{-1}$.

$a_{\mathrm{g}}[\mathrm{TPnA}]\left[\mathrm{Co}(\mathrm{dca})_{3}\right]:$ The $[\mathrm{TPnA}]\left[\mathrm{Co}(\mathrm{dca})_{3}\right]$ crystal was heated at $10^{\circ} \mathrm{C}$ $\mathrm{min}^{-1}$ to $260^{\circ} \mathrm{C}$, then cooled under an Argon atmosphere (flow rate $50 \mathrm{ml} \mathrm{min}^{-1}$ ) to $-80^{\circ} \mathrm{C}$ at $\mathrm{ca} .5^{\circ} \mathrm{C} \mathrm{min}-1$. The semi-solid (viscous) melt formed after was kept for 72 hours at room temperature to get densified (Note: Solidification of the viscous sample at room temperature might result in partial recrystallization and so 
successive heating may require to remove the remnant crystallization and achieve X-ray amorphous samples, Fig. S23c).

\section{Powder X-ray diffraction}

Ambient Temperature: X-ray powder diffraction (PXRD) patterns were recorded $\left(2 \theta=5^{\circ}-60^{\circ}\right)$ on a Bruker D8 Advance diffractometer (equipped with a LynxEye EX linear position sensitive detector) in Bragg-Brentano geometry using $\mathrm{Cu} K \alpha(\lambda=1.540598 \AA)$ source fitted with a Ni $0.012 \mathrm{~mm}$ filter. Data were collected in $2 \theta$ step size of $0.02^{\circ}$, with 10 s per step.

\section{$\mathrm{X}$-ray total scattering experiments}

Variable temperature measurements were performed on a sample of crystalline [TBuA][Mn(dca $\left.)_{3}\right],[\mathrm{TPnA}]\left[\mathrm{Mn}(\mathrm{dca})_{3}\right],[\mathrm{TPnA}]\left[\mathrm{Fe}(\mathrm{dca})_{3}\right]$ and $[T P n A]\left[\mathrm{Co}(\mathrm{dca})_{3}\right]$. Data were collected at the I15-1 beamline at the Diamond Light Source, UK $(\lambda=0.158345 \AA, 78.3 \mathrm{keV})$ in the range $0.6<Q<24 \AA^{-1}$. A finely ground sample of the crystal was loaded into a 1-mm-diameter silica capillary under Argon atmosphere using a glove box, and capped with glue along with glass wool to hold it in place during the melting process. Data were collected at a temperature of $34^{\circ} \mathrm{C}$, and then upon subsequent heating at 114,145 , $169,190,211,236,258^{\circ} \mathrm{C}$ and then back to $30^{\circ} \mathrm{C}$. Room temperature measurements were performed for $[\mathrm{TBuA}]\left[\mathrm{Mn}(\mathrm{dca})_{3}\right]$, [TBuA] $\left[\mathrm{Fe}(\mathrm{dca})_{3}\right],[\mathrm{TBuA}]\left[\mathrm{Co}(\mathrm{dca})_{3}\right]$ and $[\mathrm{TPnA}]\left[\mathrm{Mn}(\mathrm{dca})_{3}\right]$ crystalline and melt-quenched glass samples in an identical manner to those used for the high temperature measurements. Data on the sample, empty instrument and capillary were collected in the region of $0.6<$ $\mathrm{Q}<24 \AA^{-1}$. Background, multiple scattering, container scattering, Compton scattering, and absorption corrections were performed using the GudrunX program. ${ }^{33}$

Refinement of structures against pair distribution function data and calculation of partial pair distribution functions

Published structural models were refined against PDF data using PDFGui. ${ }^{34}$ Starting values used were: $Q_{\text {damp }}=0.08$, Sratio $=1$, and model scale factor $=1.0$. Values set and not refined were rcut $=5.75$ $\AA$, data scale factor $=0.5$, and $Q_{\text {broad }}=0.0001$. Isotropic thermal parameters were used for all atoms, initially set to the same value of $0.003 \AA^{2}$. Refinements were done in the range $0.5<r<20 \AA$, with $Q_{\max }=22 \AA^{-1}$.

The published structure of $[\mathrm{TBuA}]\left[\mathrm{Mn}(\mathrm{dca})_{3}\right]$ included positional disorder in the dca anion and in the A site molecule, modelled by partial occupancies of multiple sites. To enable refinement, only one of each multiple site options was chosen to give chemically sensible linkers and cations. The chosen sites were assigned full occupancy and all other sites were discarded. The final structural model was consistent with the given chemical formula. The atomic positions of the dca linkers were refined with appropriate symmetry constraints, and no positions appeared significantly different from their starting ones. The atomic positions of the A site cations were not refined, given the substantial disorder of this site. Four distinct thermal parameters for $\mathrm{Mn}, \mathrm{C}, \mathrm{H}$ and $\mathrm{N}$ were refined isotropically. Note that a good fit using this model is not expected; the disorder in the published structure strongly implies that the positions of the molecular ions will vary from one unit cell to another. It is not possible for PDFGui to accurately account for these differences using a 'small box' model based on a single unit cell and this is reflected in the relatively poor fits.

An identical treatment was also applied to the published structure of $[\mathrm{TPnA}]\left[\mathrm{Mn}(\mathrm{dca})_{3}\right]$.

\section{Magnetic study}

A SQUID MPMS 3 instrument was used to conduct the magnetic measurements of crystals and glasses. For $a_{\mathrm{g}}[\mathrm{TPnA}]\left[\mathrm{Fe}(\mathrm{dca})_{3}\right]$ and $a_{\mathrm{g}}[\mathrm{TPnA}]\left[\mathrm{Co}(\mathrm{dca})_{3}\right]$, we have used semi-solid glass samples. The temperature variation of field-cooled susceptibility $(M-T)$ data was collected at 500 Oe magnetic field at a temperature range $2-300 \mathrm{~K}$. Magnetization as a function of magnetic field $(M-H)$ was measured at temperature $300 \mathrm{~K}$, with magnetic field varying up to $7 \mathrm{~T}$. Samples were placed in a light weight homogeneous quartz tube to minimize the background noise and stray field effects. The magnetic data were corrected for the diamagnetic contribution from the quartz sample holder and the intrinsic diamagnetism of the samples by the standard literature using Pascal's constants. ${ }^{48}$

\section{CHN Elemental analysis}

The elemental compositions were obtained from $\mathrm{CHN}$ analyzer. Ground powder samples (semi-solid viscous samples for $a_{\mathrm{g}}[\mathrm{TPnA}]\left[\mathrm{Fe}(\mathrm{dca})_{3}\right]$ and $a_{\mathrm{g}}[\mathrm{TPnA}]\left[\mathrm{Co}(\mathrm{dca})_{3}\right]$,) were used to perform the measurements using CE440 Elemental Analyzer, EAl Exeter Analytical Inc.

\section{References}

1 C. Eames, J. M. Frost, P. R. F. Barnes, B. C. O'Regan, A. Walsh and M. S. Islam, Nat. Commun., 2015, 6, 7497.

2 G. Y. Kim, A. Senocrate, T.-Y. Yang, G. Gregori, M. Grätzel and J. Maier, Nat. Mater., 2018, 17, 445-449. Y. Tian, S. Shen, J. Cong, L. Yan, S. Wang and Y. Sun, J. Am. Chem. Soc., 2016, 138, 782-785.

4 M. Liu, M. B. Johnston and H. J. Snaith, Nature, 2013, 501, 395-398.

$5 \quad$ M. M. Lee, J. Teuscher, T. Miyasaka, T. N. Murakami and H. J. Snaith, Science, 2012, 338, 643-647. B. Zhao, S. Bai, V. Kim, R. Lamboll, R. Shivanna, F. Auras, J. M. Richter, L. Yang, L. Dai, M. Alsari, X.-J. She, L. Liang, J. Zhang, S. Lilliu, P. Gao, H. J. Snaith, J. Wang, N. C. Greenham, R. H. Friend and D. Di, Nat. Photonics, 2018, 12, 783-789.

7 D. Luo, W. Yang, Z. Wang, A. Sadhanala, Q. Hu, R. Su, R. Shivanna, G. F. Trindade, J. F. Watts, Z. Xu, T. Liu, K. Chen, F. Ye, P. Wu, L. Zhao, J. Wu, Y. Tu, Y. Zhang, X. Yang, W. Zhang, R. H. Friend, Q. Gong, H. J. Snaith and R. Zhu, Science, 2018, 360, 1442-1446.

8 W. Li, Z. Wang, F. Deschler, S. Gao, R. H. Friend and A. K. Cheetham, Nat. Rev. Mater., 2017, 2, 16099.

9 Y. Wu, S. Shaker, F. Brivio, R. Murugavel, P. D. Bristowe and A. K. Cheetham, J. Am. Chem. Soc., 2017, 139, 1699917002.

10 Y. Tian, A. Stroppa, Y. Chai, L. Yan, S. Wang, P. Barone, S. Picozzi and Y. Sun, Sci. Rep., 2015, 4, 6062.

11 W. Li, A. Stroppa, Z. Wang and S. Gao, Hybrid OrganicInorganic Perovskites, Wiley, 2020.

12 J. Albero, A. M. Asiri and H. García, J. Mater. Chem. A, 2016, 4, 4353-4364. H. Furukawa, K. E. Cordova, M. O'Keeffe and O. M. Yaghi, Science, 2013, 341, 1230444-1230444. M. Ptak, K. L. Svane, A. Walsh and W. Paraguassu, Phys. Chem. Chem. Phys., 2019, 21, 4200-4208.
P. C. Rout and V. Srinivasan, Phys. Rev. Mater., 2018, 2, 014407. 
H. Furukawa, K. E. Cordova, M. O’Keeffe and O. M. Yaghi, Science, 2013, 341, 1230444.

17 J. M. Bermúdez-García, M. Sánchez-Andújar, S. Yáñez-Vilar, S. Castro-García, R. Artiaga, J. López-Beceiro, L. Botana, A. Alegría and M. A. Señarís-Rodríguez, J. Mater. Chem. C, 2016, 4, 4889-4898.

18 J. M. Bermúdez-García, M. Sánchez-Andújar, S. CastroGarcía, J. López-Beceiro, R. Artiaga and M. A. SeñarísRodríguez, Nat. Commun., 2017, 8, 15715. J. M. Bermúdez-García, M. Sánchez-Andújar, S. Yáñez-Vilar, S. Castro-García, R. Artiaga, J. López-Beceiro, L. Botana, Á. Alegría and M. A. Señarís-Rodríguez, Inorg. Chem., 2015, 54, 11680-11687. C. Ablitt, S. Craddock, M. S. Senn, A. A. Mostofi and N. C. Bristowe, npj Comput. Mater., 2017, 3, 44.

21 M. Mączka, A. Gągor, M. Ptak, D. Stefańska, L. Macalik, A. Pikul and A. Sieradzki, Dalt. Trans., 2019, 48, 13006-13016. B. K. Shaw, A. R. Hughes, M. Ducamp, S. Moss, A. Debnath, A. F. Sapnik, M. F. Thorne, L. N. McHugh, A. Pugliese, D. S. Keeble, P. Chater, J. M. Bermudez-Garcia, X. Moya, S. K. Saha, D. A. Keen, F.-X. Coudert, F. Blanc and T. D. Bennett, Nat. Chem., 2021, DOI:10.1038/s41557-021-00681-7. M. Wang, V. Vasudevan, S. Lin, J. Jasieniak, S. P. Russo, N. Birbilis and N. V. Medhekar, J. Mater. Chem. A, 2020, 8, 17765-17779.

24 C. Healy, K. M. Patil, B. H. Wilson, L. Hermanspahn, N. C. Harvey-Reid, B. I. Howard, C. Kleinjan, J. Kolien, F. Payet, S. G. Telfer, P. E. Kruger and T. D. Bennett, Coord. Chem. Rev., 2020, 419, 213388. R. Gaillac, P. Pullumbi, K. A. Beyer, K. W. Chapman, D. A. Keen, T. D. Bennett and F.-X. Coudert, Nat. Mater., 2017, 16, 1149-1154. T. D. Bennett and S. Horike, Nat. Rev. Mater., 2018, 3, 431440.

S. S. Nagarkar, H. Kurasho, N. T. Duong, Y. Nishiyama, S. Kitagawa and S. Horike, Chem. Commun., 2019, 55, 54555458.

L. Frentzel-Beyme, M. Kloß, R. Pallach, S. Salamon, H. Moldenhauer, J. Landers, H. Wende, J. Debus and S. Henke, J. Mater. Chem. A, 2019, 7, 985-990. V. M. Goldschmidt, Naturwissenschaften, 1926, 14, 477485. J. A. Schlueter, J. L. Manson and U. Geiser, Inorg. Chem., 2005, 44, 3194-3202.

31 F. L. Lambert, J. Chem. Educ., 2007, 84, 1548.

32 M. Liu, R. D. McGillicuddy, H. Vuong, S. Tao, A. H. Slavney, M. I. Gonzalez, S. J. L. Billinge and J. A. Mason, J. Am. Chem. Soc., 2021, jacs.0c11718.

A. K. Soper, GudrunN and GudrunX: Programs for Correcting Raw Neutron and X-ray Diffraction Data to Differential Scattering Cross Section. Tech. Rep. RAL-TR2011-013, 2011. C. L. Farrow, P. Juhas, J. W. Liu, D. Bryndin, E. S. Božin, J. Bloch, T. Proffen and S. J. L. Billinge, J. Phys. Condens. Matter, 2007, 19, 335219. C. Chakravarty, P. G. Debenedetti and F. H. Stillinger, J. Chem. Phys., 2007, 126, 204508. G. Kieslich, S. Sun and A. K. Cheetham, Chem. Sci., 2014, 5, 4712-4715.
Front. Chem., , DOI:10.3389/fchem.2018.00059.

D. R. MacFarlane, S. A. Forsyth, J. Golding and G. B. Deacon, Green Chem., 2002, 4, 444-448.

J. M. Bermúdez-García, S. Yáñez-Vilar, A. García-Fernández, M. Sánchez-Andújar, S. Castro-García, J. Mira, J. A. Moreira, T. A. Centeno and M. A. Señarís-Rodríguez, New J. Chem., 2017, 41, 3124-3133.

E. Kroke, M. Schwarz, E. Horath-Bordon, P. Kroll, B. Noll and A. D. Norman, New J. Chem., 2002, 26, 508-512. K. Täuber, A. Dani and J. Yuan, ACS Macro Lett., 2017, 6, 15. S. Jana, B. K. Shaw, P. Bhowmik, K. Harms, M. G. B. Drew, S. Chattopadhyay and S. K. Saha, Inorg. Chem., 2014, 53, 8723-8734.

B. K. Shaw, M. Das, A. Bhattacharyya, B. N. Ghosh, S. Roy, P. Mandal, K. Rissanen, S. Chattopadhyay and S. K. Saha, RSC Adv., 2016, 6, 22980-22988.

K. Chattopadhyay, B. K. Shaw, S. K. Saha and D. Ray, Dalt. Trans., 2016, 45, 6928-6938.

B. K. Shaw and S. K. Saha, J. Phys. Chem. C, 2012, 116, 20700-20707.

B. K. Shaw and S. K. Saha, J. Magn. Magn. Mater., 2014, 365, 138-144.

G. A. Bain and J. F. Berry, J. Chem. Educ., 2008, 85, 532. 
